\title{
Evaluation of the readiness of nurse anesthetists in Ghana for a master's degree completion program: An exploratory, observational study
}

\author{
Philip Kwame Kwetey, Donna Nyght, Paul Bennetts \\ University of Kansas Medical Center, United States
}

Received: March 28, 2019

DOI: $10.5430 /$ jnep.v9n11p114
Accepted: August 30, 2019

Online Published: September 12, 2019

URL: https://doi.org/10.5430/jnep.v9n11p114

\begin{abstract}
Ghana is a developing country in West Africa with limited anesthesia providers impacting surgical access and anesthesia safety. There are only two anesthesia providers per 100,000 population, with the majority of providers being nurse anesthetists, most of whom hold only diplomas, and more recently, bachelor's in anesthesia education. This paper reports an observational study exploring the prospects of an advanced degree at the master's degree level for practicing nurse anesthetists in Ghana. Three focus groups and one semi-structured individual interview were conducted with a total of 69 participants. Four major themes emerged following data analysis: desire for improved clinical expertise; focus on research methods to improve patient outcomes; perceived inadequate physician support for graduate nurse anesthetists (NA) education and infrastructure; and desires for an advanced degree for career progression. Findings highlight the readiness of nurse anesthetists in Ghana for an advanced degree and the necessary infrastructure and needed areas of clinical anesthesia education and research that must be included in the curriculum development for a master's level education.
\end{abstract}

Key Words: Advanced degree, Education, Nurse anesthetist, Mater's completion curriculum, Clinical expertise

\section{INTRODUCTION}

The majority of current anesthesia providers in Ghana, West Africa, are nurse anesthetists (NAs). The availability of qualified anesthesia providers is central to the promotion of anesthesia safety and surgical patient outcomes in Ghana. In a recent report, Brouillette et al. (2016 ${ }^{[1]}$ stated that there are 70 anesthesia attending physicians and 565 nurse anesthetists for Ghana's 28 million population. Thus, over $85 \%$ of anesthesia providers are nurse anesthetists, most of whom hold only diplomas or, more recently, bachelor's degrees in anesthesia. Compounding this problem is the fact that physician anesthesiologists are heavily concentrated in the urban areas, leaving nurse anesthetists to practice independently in rural hospitals and clinics in eight out of the ten regions in

\section{Ghana.}

The ratio of two anesthesia providers per 100,000 population is grossly inadequate to enable sufficient surgical access and promote anesthesia safety for most of Ghanaians. This shortage of anesthesia providers may be contributing to the high rate of anesthesia-related morbidity and mortality, estimated to be 1 per 1000, which is among the highest in Sub-Sahara Africa. ${ }^{[2]}$ The same study by Brouillette et al. (2016) in Ghana at a teaching hospital staffed with both attending anesthesiologists and nurse anesthetists noted that from 2011 to 2015 , all-cause perioperative mortality rate in operating rooms (ORs) and post-anesthesia care units (PACUs) was $0.65 \%$ or 1 death per 154 anesthetics. This mortality rate

*Correspondence: Philip Kwame Kwetey; Email: philipkwetey1@yahoo.com; Address: University of Kansas Medical Center, United States. 
might even be higher in poorly-equipped district and rural hospitals inadequately staffed with only diploma level nurse anesthetists. ${ }^{[3,4]}$ The unacceptable number of deaths prompted multiple surveys leading advocates to suggest the need to expand nurse anesthesia education and training to improve anesthesia safety. ${ }^{[5]}$ The suggested need for a higher level of education for nurse anesthetists led to the development of the Bachelor of Science in nurse anesthesia program which currently trains practicing nurses who want to become NAs as well as practicing diploma nurse anesthetists who want to advance their education to the bachelor's degree level. There are only three bachelor's degree programs in the country for nurse anesthesia.

The current bachelor's program at the School of Anesthesia Kumasi, Ghana (SOAK) is a two-year program for practicing nurses with either a diploma or bachelor's degree in nursing science. In contrast to nurse anesthesia education in the United States, critical care nursing experience is not required. The curriculum for the bachelor's program has both didactic and clinical components that must be completed prior to graduation. New students begin clinical observation after eight weeks of didactic work. The weeks following are divided between didactic (usually Mondays, Wednesday and Fridays) and clinicals (Tuesdays, Thursdays and Saturdays) as seen in Figure 1. A minimum of 28 hours of clinicals per week is required compared to 36-40 hours per week in the United States. Arterial and central line insertion are not required even though students are made to observe and assist during line insertion. Case load totals for graduation are comparable to that required in the United States.

\begin{tabular}{|c|c|c|c|c|c|c|c|}
\hline DAYS & 08:00-10:00 & $10: 00-12: 00$ & $\begin{array}{l}12: 00- \\
13: 00\end{array}$ & $\begin{array}{l}13: 10- \\
15: 10\end{array}$ & $15: 10-16: 40$ & $\begin{array}{l}16: 40- \\
17: 05\end{array}$ & $\begin{array}{l}17: 10- \\
18: 40\end{array}$ \\
\hline \multirow[t]{2}{*}{ Monday } & \multicolumn{2}{|l|}{ 09:00-12:00 } & \multirow[t]{2}{*}{ Break } & \multirow{2}{*}{$\begin{array}{l}\text { Critical } \\
\text { Care } \\
\text { Medicine } \\
\text { II }\end{array}$} & \multirow{2}{*}{$\begin{array}{l}\text { Specialized } \\
\text { Anesthesia II }\end{array}$} & \multirow[t]{2}{*}{ Break } & \multirow{2}{*}{$\begin{array}{l}\text { Practical } \\
\text { Conduct of } \\
\text { Anesthesia } \\
\text { II }\end{array}$} \\
\hline & \multicolumn{2}{|c|}{$\begin{array}{l}\text { Principles and Practice of } \\
\text { Anesthesia II }\end{array}$} & & & & & \\
\hline Tuesday & \multicolumn{7}{|c|}{ Practical Conduct of Anesthesia III (Operation Room Session) } \\
\hline Wednesday & $\begin{array}{l}\text { Research Methods and } \\
\text { Biostatistics }\end{array}$ & $\begin{array}{ll}\text { Critical care } \\
\text { Medicine II }\end{array}$ & Break & $\begin{array}{l}\text { Medico- } \\
\text { legal }\end{array}$ & $\begin{array}{l}\text { Pain } \\
\text { Management } \\
\text { and Control }\end{array}$ & Break & \\
\hline Thursday & \multicolumn{5}{|c|}{ Practical Conduct of Anesthesia III (Operation Room Session) } & & \\
\hline Friday & $\begin{array}{l}\text { Research Methods and } \\
\text { Biostatistics }\end{array}$ & $\begin{array}{l}\text { Specialized } \\
\text { Anesthesia II }\end{array}$ & Break & \begin{tabular}{|l} 
Medico- \\
legal
\end{tabular} & $\begin{array}{l}\text { Critical Care } \\
\text { Medicine II }\end{array}$ & Break & $\begin{array}{l}\text { Practical } \\
\text { Conduct of } \\
\text { Anesthesia } \\
\text { III }\end{array}$ \\
\hline Saturday & \multicolumn{7}{|c|}{ Practical Conduct of Anesthesia III } \\
\hline
\end{tabular}

Figure 1. Sample of weekly NA schedule at the School of Anesthesia, Kumasi-Ghana

In the United States, the need for rural independent nurseanesthesia practitioners has benefited from graduate-level education and training which enhances the nurse anesthetist's ability to synthesize information and make evidence-guided decisions. ${ }^{[6]}$ The growing complexity of today's healthcare environment, the rapid expansion of knowledge required to practice independently, and societal expectations of quality anesthesia care underscores the need for advanced degree in nurse anesthesia education in Ghana as well. ${ }^{[7-9]}$ To date, no studies have been conducted to evaluate the prospects of graduate-level education for nurse anesthetists in Ghana. This study aimed to answer the following research questions: 1) What are the perceptions of practicing NA's, NA students, and physician anesthesiologists regarding the potential benefits of advanced anesthesia education for Ghanaian NAs? 2) What are the barriers to advanced nurse anesthesia education in Ghana?

Published by Sciedu Press

\section{METHODS}

A qualitative observational study method with individual interviews and focus group discussions was used for data collection.

\subsection{Sample}

A total of 69 participants, including physician anesthesiologists (2), nurse anesthesia students (56), nurse anesthesia education faculty (1), and practicing nurse anesthetists (10) from the School of Anesthesia and Komfo Anokye Teaching Hospital (KATH) in Kumasi, Ghana; were included in the study. KATH is one of Ghana's two teaching hospitals. It is a nationally recognized level-one trauma referral hospital. A wide range of surgical procedures are performed each year at $\mathrm{KATH}$, including obstetrics, pediatric, and general surgery. 
Table 1. Participants

\begin{tabular}{llll}
\hline Focus Group & No. of Participants & Gender & Profession \\
\hline Focus Group 1 & 2 & Male $\mathrm{n}=2$ & Physician Anesthesiologist \\
Interview & 1 & Male $\mathrm{n}=1$, & NA education program coordinator \\
Focus Group 2 & 10 & Male $\mathrm{n}=7$, Female $\mathrm{n}=3$ & Practicing NAs \\
Focus Group 3 & 56 & Male $\mathrm{n}=47$, Female $\mathrm{n}=9$ & Nurse anesthesia students \\
\hline
\end{tabular}

\subsection{Data collection methods and tools}

Participants were given 90 days of advance notice, through emails and telecommunications, of our visit. Two senior NA students and a faculty member all from the University of Kansas NA education department visited Ghana. Data collection took place during September 2018. Three focus groups and one semi-structured individual interview were conducted. Open-ended questions were used to encourage participants to express their views concerning the subject of discussion. Discussions focused on:

- Current education and practice of NAs, and the prospects of a master's completion program for NAs in Ghana. Participants were encouraged to focus specifi- cally on the merits, limitations, and hinderances of an advanced degree for NAs.

- Areas of focus of the curriculum for an advanced degree to enhance anesthesia safety and practice unique to the Ghanaian healthcare system.

Operating room observations were also utilized to gain firsthand knowledge about anesthesia practices in Ghana.

\subsection{Data analysis}

The interviews were summarized. Emerging topics from the focus group discussions and interview are presented in Table 2.

Table 2. Focus groups discussion summaries

\begin{tabular}{|c|c|}
\hline Focus Group & Summaries \\
\hline $\begin{array}{l}\text { Physician } \\
\text { Anesthesiologist }\end{array}$ & $\begin{array}{l}\text { Advanced degree will improve clinical research methods. } \\
\text { Evidence Based Practice needed to improve patient surgical outcomes and decrease gap between } \\
\text { research and practice. } \\
\text { Timing for master’s degree premature, current bachelor’s program must be improved first before } \\
\text { pursuing an advanced degree. }\end{array}$ \\
\hline $\begin{array}{l}\text { NA Program } \\
\text { Coordinator }\end{array}$ & $\begin{array}{l}\text { Advanced degree will improve patient safety and outcomes. } \\
\text { Will enhance public outlook on safety of healthcare system. } \\
\text { Master's degree will enhance career progression and help mitigate the anesthesia provider shortage in } \\
\text { rural Ghana. } \\
\text { Inadequate infrastructure will delay implementation of this program. }\end{array}$ \\
\hline $\begin{array}{l}\text { Practicing } \\
\text { NAs }\end{array}$ & $\begin{array}{l}\text { Advanced degree will help improve knowledge and clinical expertise. } \\
\text { The clinical component of this program will help acquire the skills needed for independent practice. } \\
\text { It will pave a way for career progression and attract potential candidates to improve provider numbers. } \\
\text { Evidence Based Practice (EBP) component will help reduce anesthesia related morbidity and mortality. }\end{array}$ \\
\hline NA Students & $\begin{array}{l}\text { An advanced degree will help alleviate the brain drain negatively affecting the numbers of anesthesia } \\
\text { providers in Ghana. } \\
\text { Will help train providers who are adequately prepared for independent practice. } \\
\text { Research methods are critical to understanding and interpreting research works. } \\
\text { Bargaining power will be enhanced to improve conditions of living for NAs. }\end{array}$ \\
\hline
\end{tabular}

\section{Findings}

Four major themes emerged from the collected data: desire for improved clinical expertise; focus on research methods to improve patient outcomes; perceived inadequate physician support for graduate NA education and infrastructure; and desires for an advanced degree for career progression.

\subsection{Desire for improved clinical expertise}

There was a general feeling that NAs are denied certain clinical skills needed for a successful (independent) nurse anesthesia practice. Some of the NAs felt this was a way of limiting their scope of practice by physician anesthesiologists who supervise the bachelor's degree programs for NAs. 
Nurse anesthetists are taught how to perform spinal anesthesia, but peripheral and epidural blocks, as well as central line placement are deemed outside their scope of practice and therefore not part of their curriculum. One practicing NA described a rather painful experience with tears of how this practice limitation affected him personally: "this patient died because he needed a central line access to save his life and I wasn't taught how to place a central line, and the anesthesiologist was not available at the time. I was hurt by this experience because this was someone I knew personally". Some also expressed similar experiences of helplessness in their inability to perform life-saving skills to save lives or help patients needing pain management.

There was an agreement among students and practicing NAs that an advanced degree will improve their skill-set and expand their clinical expertise in providing quality care for their patients, especially in certain district and rural hospitals where anesthesiologists are unavailable. The ability to place an epidural for a patient in labor or a peripheral block for pain control are foundational prerequisites for anesthesia practice in the United States. One nurse anesthetist reflected: "How can you be an independent provider when you're not taught how to perform certain skills needed to save lives? This must change and the way to do it is through education." (NA). Participants who work in rural hospitals passionately expressed concerns about their inability to perform central line placements or epidurals when the need arises. The district hospitals and clinics staffed by nurse anesthetists see an array of complex obstetrics and trauma cases on daily basis. It is frequently unsafe to transfer these patients to regional urban hospitals due to long distances, poor road conditions or unavailability of trained emergency transport teams. These nurse anesthetists are compelled to provide care to the best of their educational preparation and experiences, sometimes with unsuccessful outcomes. In addition to negative patient outcomes, the interviewees also spoke of the psychological trauma they experience as a result. Their desire to help others in need underscore the enthusiasm to see access to an advanced degree for NAs in Ghana.

The feelings expressed were also echoed by practicing NAs observed during our OR visits. Nurse anesthetists or nurse anesthesia students are frequently the primary in-room providers at KATH, practicing independently during most phases of anesthesia care. They perform inductions, maintenance and emergence from anesthesia most of the time without a physician anesthesiologist present. Staff anesthesiologists are available to assist in an emergency. Some of the surgeons who have worked with nurse anesthetists for decades expressed their satisfaction with their skills, expertise and safety profile. They have a cordial working rela-

Published by Sciedu Press tionship and NAs are deemed as a great resource for surgical access and patient outcomes. Despite limited resources and unavailability of modern anesthesia supplies and equipment ${ }^{[10]}$ Ghanaian NAs are at the forefront doing their best to provide anesthesia care to patients and their families.

\subsection{Focus on research methods to improve patient out- comes}

There was some disagreement among participants concerning the essentials of an advanced degree curriculum for nurse anesthesia, unique to Ghana's healthcare system ${ }^{[11]}$ that would improve surgery, anesthesia outcomes, and patient safety. "What we currently lack in our healthcare system is research, I am more interested in research methods; that is the main way to improve patient safety and outcomes," said one staff anesthesiologist. Students enrolled in the nurse anesthesia education program are required to conduct some form of research work for graduation. It is clear from the discussions that research methods are seen as important to effecting change guided by evidence, however research skills are typically not part of undergraduate education and could best be developed through master's-level education.

In developed countries, movement toward evidence-based practice (EBP) has been possible primarily due to the emphasis on developing programs of clinical research. ${ }^{[12-16]}$ "It is important for us to realize that research guides practice, and practice in turn feeds research, the two are inseparable" (staff anesthesiologist). Healthcare delivery in Ghana is under the direction of the Ministry of Health ( $\mathrm{MOH})$, a governmental agency that is responsible for securing funds for the public hospitals every fiscal year. Any request for additional funds must be backed by a compelling evidence of how it would improve access and outcomes. Participants view research methodology as critical to acquiring governmental funds to effectively run the healthcare institutions. Moreover, "patients will see the improvement in the care we deliver and would not hesitate to seek medical care when the need arises. Currently, a lot of Ghanaians prefer to rather seek herbalists and faith healers than come to the hospital for fear of untoward outcomes" (NA)

It was agreed that the proposed master's curriculum be amended to include research methods in the first semester (see Figure 2). Students will be introduced early to research methodology and be assisted to choose their individual area or topic of research so that they would have two years to work on these topics: "currently students have less than six months to work on a research topic which is inadequate to ensuring successful research. The earlier they start, the better the odds of completing a thorough research work prior to graduation" (faculty member). 


\begin{tabular}{|c|c|}
\hline YEAR 1 & YEAR 1 \\
\hline First Semester & Second semester \\
\hline Advanced Physical Assessment - & Advanced Pharmacology II - \\
\hline Advanced Pharmacology I- & Advanced Anesthesia Theory (OB/PEDS) - \\
\hline Advanced pathophysiology - & EBP- QI and Safety in Anesthesia Care - \\
\hline Total $=$ & Total $=$ \\
\hline YEAR 2 & YEAR 2 \\
\hline Third Semester & Forth Semester \\
\hline $\begin{array}{l}\text { Pain Management and Introduction to } \\
\text { USG Regional Anesthesia - }\end{array}$ & $\begin{array}{l}\text { Anesthesia Theory-(Critical } \\
\text { care/Trauma/Cardiac/Burn) - }\end{array}$ \\
\hline $\begin{array}{l}\text { Advanced Anesthesia Theory } \\
\text { (Neuro/GYN/GIENT) - } \\
\text { Education in Nurse Anesthesia - }\end{array}$ & $\begin{array}{l}\text { Masters Scholarly Project - } \\
\text { Leadership in Anesthesia-- }\end{array}$ \\
\hline Total $=$ & Total $=$ \\
\hline
\end{tabular}

Figure 2. Tentative Master of science in nurse anesthesia completion program curriculum

\subsection{Perceived inadequate physician support and infras- tructure}

There was a general concern among nurse anesthetists that some physician anesthesiologists would not support any attempt to advance their education and career. Some believe this is so because the current bachelor's degree at KATH is directed by physician anesthesiologists: "currently we simply don't have nurse anesthetists with advance degrees in anesthesia to teach or run a master's degree program, meaning we would have to rely on physician anesthesiologists, some of who will not support the idea of a master's degree for nurse anesthetists" (NA)

Among physician anesthesiologists, there was a disagreement concerning the timing and the need for an advanced degree for nurse anesthetists. One believes the idea is illadvised currently because the bachelor's program is still in its infancy and needs time for full implementation before talking about an advanced degree. Furthermore, "students admitted into the bachelor's program often lack the foundational sciences in physics, chemistry, and biology required for a science major. These are nurses with little science background being admitted into a course of study that depends heavily on sciences. We had to somehow lower our admission criteria to be able to admit these students into the program. We were forced to seek accreditation from another university because the university here demands that students admitted into any major science course obtain a grade of $\mathrm{C}$ or better in the foundational sciences which is simply impossible for us to require of these students. We need time to figure all this out first before taking the next step toward a master's degree program" (staff anesthesiologist).

This view was sharply opposed to by another participant: "the nurses are already into anesthesia practice even without strong science backgrounds. Why can't we train them to improve upon their previously acquired knowledge and skill? Besides, we need research to inform the way we practice anesthesia. Advanced degrees are for this very purpose, research. The time is now, and you have my full support" (staff anesthesiologist). These opposing views of an advanced degree for nurse anesthetists poses a major roadblock in the pursuance of such a program. Again, the lack of infrastructure is another impediment that was discussed at length: "we are not admitting students this year into the bachelor's program because we don't have any classrooms for these students. We have only one classroom for the current students and so we have to graduate them next year before we can admit anybody else into the program" (faculty member). The 2018-2019 academic year will have no first-year students for lack of classrooms for instruction.

\subsection{Desires for an Advanced degree for career progres- sion}

Many participants believed that an advance degree will boost career progression opportunities for nurse anesthetists in Ghana and possibly West Africa: "because there was nothing else to study after my diploma, I was compelled to study Master of Business Administration, a subject not related to anesthesia" (NA). Before the start of the bachelor of nurse anesthesia program, nurse anesthetists have no career progression after completing the diploma in anesthesia education program. Those who want to advance their education are compelled to undertake subjects in universities mostly unrelated to anesthesia, including theology, anatomy, physiology, nursing, business, and administration. Others go on to obtain a general master's in nursing science which has little application to anesthesia. "I was glad when I heard of your visit because we have been waiting for decades for an opportunity like this to advance our career and knowledge to be good at what we do" (Faculty member).

Most other healthcare professions such as general nursing, laboratory science and radiology have advanced programs beyond bachelor's degree. There is a consensus that it is time for nurse anesthesia education in Ghana to advance. ${ }^{[17-21]}$ There was also a recognition that anesthesia practice has advanced over the years compared to the 1960s when the diploma program was first introduced in Ghana: the only way to catch up to today's advancement in the science of anesthesia is through advanced education which is currently unavailable to nurse anesthetists (NA).

\section{Discussion}

This qualitative exploratory study was aimed at evaluating the current systems of nurse anesthesia education and practice and explore the possibility of developing a master's degree completion curriculum for practicing nurse anesthetists who already have the bachelor's degree. Four important themes 
were identified: desire for improved clinical expertise; focus on research methods to improve patient outcomes; perceived inadequate physician support and infrastructure, and desires for an advanced degree for career progression.

\subsection{Implications for education and practice}

Nurse anesthetists provide most of the anesthesia care across the country. Except in the urban and teaching hospitals, nurse anesthetists practice independently without physician supervision. These nurse anesthetists receive less than two years of education and training and are awarded advanced diploma in nurse anesthesia. The limited education and number of years spent in school are inadequate to cover all areas of procedural skills and expertise needed to practice independently across all surgical specialties and patient population. Surgical specialties including neurosurgery and orthopedics, are expanding at a faster rate in Ghana. Preparations are underway at KATH for an advanced cardiothoracic surgery center. Nurse anesthetists need the education and training that will prepare them for these specialty areas.

Our observations support an advanced degree that incorporates all areas of clinical skills and knowledge needed for independent practice. For example, pharmacology as thought currently at the bachelor's degree level is limited to anesthesia related pharmacologic agents. This is limited in scope and NAs are not exposed to how other pharmacotherapeutic agents affect and impact the outcome of anesthesia. In the age of growing understanding of complex human pathologies, it is imperative for anesthesia providers to be grounded in clinical pharmacology well beyond those utilized by anesthetists, and to understand how these agents impact anesthesia safety. Therefore, an advanced degree that incorporates human pathologies and how various classes of pharmacologic agents affect anesthesia outcomes is recommended. Moreover, advanced clinical skillsets, such as placement of central lines, ultrasound guided regional anesthesia, and epidural anesthesia will make these modalities more widely available in Ghana and help promote anesthesia safety and patient satisfaction. ${ }^{[22,23]}$

In a system struggling to improve anesthesia-related morbidity and mortality, research becomes the cornerstone of gathering and interpreting evidence to inform clinical practice. It is evident from our findings that physician anesthesiologists and nurse anesthetists support an advanced degree that incorporates and promotes research methods and interpretation of research findings. This will also promote the utilization of research among nurse anesthetists. There are an array of research works on almost everything we do in anesthesia practice, from clinical skills to the safety of pharmacologic agents utilized in the provision of anesthesia. It is impera-

Published by Sciedu Press tive for anesthesia providers to be well grounded not only in the conduct of research, but also the application of research findings into clinical practice. Through this, the gap between research and clinical application will be minimized.

Nurse anesthetists with advanced degrees in related science disciplines in anatomy, physiology, nursing science and other related health sciences will be a resource in the implementation of an advanced degree for NAs. An advanced degree in nurse anesthesia education would be offered through a university with an established Board that oversees research. Adequate infrastructure and physician anesthesiology involvement are critical for a successful implementation of such a program. Didactic knowledge and clinical skills required of an independent practitioner must be incorporated into the program so that candidates are well prepared to practice safe anesthesia.

In the meantime, it is important that the Bachelor of Science in nurse anesthesia degree programs be strengthened especially in comprehensive intraoperative monitoring. For example, electrocardiography (EKG) tracings, interpretation and treatment of common dysrhythmias are currently not taught at the Bachelor of Science in nursing degree levels. This became evident during our operating room observations that first year students in NA program lack the basic knowledge for EKG interpretation. Understanding of patient monitoring and interpretation are fundamental for a successful anesthesia care.

\subsection{Limitations}

This study was conducted at a single nurse anesthesia education program and may not necessary reflect NA education at other institutions. Because only one class was in the program at our visit, final year students in the NA program were not available to participate in this study to provide more comprehensive knowledge of their readiness for independent practice. Moreover, time spent for operating room observations was insufficient to fully assess how anesthesia is conducted especially during complex cases as it relates to venous and arterial access placement, and availability of tools and equipment. Additional visits to KATH to add to our understanding of the educational need of the NA students are being planned. Nonetheless, this study provides insight into the prospects of an advanced degree for NAs in Ghana, especially in the areas of research and clinical expertise.

\section{Conclusion}

We evaluated the current systems of nurse anesthesia education and practice and assessed the prospects of an advanced degree for nurse anesthetists in Kumasi, Ghana. Findings highlight the readiness of nurse anesthetists for such a pro- 
gram for improved clinical expertise, research methodology, anesthesia safety, and career progression. Strengthening of the current bachelor's program to adequately prepare graduates for an advanced degree is warranted. An advanced degree that equips nurse anesthetists with the knowledge and skills required for independent practice is paramount to improving anesthesia related morbidity and mortality in Ghana's healthcare system.

\section{ACKNOWLEDGEMENTS}

The faculty of the University of Kansas Nurse Anesthesia education for their support, especially Dr. Paul Bennetts for his immense contribution and guidance in completing this study.

\section{CONFlicts OF InTEREST Disclosure}

The authors declare that there is no conflict of interest.

\section{REFERENCES}

[1] Brouillette MA, Aidoo AJ, Hondras MA, et al. Anesthesia Capacity in Ghana: A Teaching Hospital's Resources, and the National Workforce and Education. International Anesthesia Research Society. 2016.

[2] Potisek MG, Hatch DM, Atito-Narh E, et al. Where Are They Now? Evolution of a Nurse Anesthesia Training School in Ghana and a Survey of Graduates. Frontiers in Public Health. 2017. PMid:28451585 https://doi.org/10.3389/fpubh. 2017.00078

[3] Bainbridge D, Martin J, Arango M, et al. Anaesthetic-related mortality in sub-Saharan Africa - Authors' reply. Lancet. 2012 Sep 22; 380(9847): 1075-81; Lancet. 2013 Jan 19; 381(9862): 199. https : //doi.org/10.1016/S0140-6736(13)60081-1

[4] Gyedu A, Abantanga F, Boakye G, et al. Barriers to essential surgical care experienced by women in the two northernmost regions of Ghana: a cross-sectional survey. BMC Women's Health. 2016; 16(1). PMid:27230890 https ://doi.org/10.1186/s12905-016-030 8-4

[5] Choo S, Perry H, Hesse AAJ, et al. Assessment of capacity for surgery, obstetrics and anaesthesia in 17 Ghanaian hospitals using a WHO assessment tool. Tropical Medicine \& International Health. 2016; 15(9): 1109-1115.

[6] Hawkins R, Nezat G. Doctoral education: which degree to pursue? AANA Journal. 2009; 77(2).

[7] Wong A. Review article: teaching, learning, and the pursuit of excellence in anesthesia education. Canadian Journal of Anesthesia. 2012; 59(2): 171-181. PMid:22135210 https://doi.org/10.1007/s1 2630-011-9636-x

[8] Dohlman LE. Providing anesthesia in resource-limited settings. Current Opinion in Anesthesiology. 2017; 30(4): 496-500. PMid:28426446 https: //doi.org/10.1097/AC0.0000000000 000477

[9] Education IFNA. 2016, June 14. Available from: http://ifna.s ite/etusivu/education-2. Ghana: countryprofiles

[10] Hadler RA, Chawla S, Stewart BT, et al. Anesthesia Care Capacity at Health Facilities in 22 Low- and Middle-Income Countries. World Journal of Surgery. 2016; 40(5): 1025-1033. PMid:26822158 https ://doi .org/10.1007/s00268-016-3430-4

[11] Oduro KA. Anesthesia in Ghana. A review with particular reference to the indigenous medical conditions. Anesthesia. 2015; 24(3): 307316. PMid:5791057 https ://doi .org/10.1111/j .1365-2044. 1969.tb02869.x
[12] Hall HR, Roussel L. Evidence-based practice: An integrative approach to research, administration, and practice. Burlington, MA: Jones \& Bartlett Learning. 2014.

[13] Hamric AB, Hanson CM, Tracy MF, et al. Advanced practice nursing: An integrative approach. St. Louis, MI: Elsevier Saunders; 2014.

[14] In Mateo MA, In Foreman MD. Research for Advanced Practice Nurses: From Evidence to Practice. 2nd ed. New York, NY: Springer Pub; 2014.

[15] Polit DF, Beck CT. Nursing research: Generating and assessing evidence for nursing practice. 9th ed. Philadelphia, PA: Wolters Kluwer, Lippincott Williams \& Wilkins. 2012.

[16] Caulk RF, Ouellette SM. The International Federation of Nurse Anesthetists: its role in the globalization of nurse anesthesia education and practice. CRNA: The Clinical Forum for Nurse Anesthetists. 2000; 11(3): 132-137.

[17] Peters J, Boakye G, Harris M, et al. Anesthesia teaching in Ghana: a 10-year experience. International Anesthesiology Clinics. 2010; 48(2): 23-37. PMid:20386224 https://doi.org/10.1097/AIA. Ob013e3181cd1603

[18] Olufolabi A, Atito-Narh E, Eshun M, et al. Teaching Neuraxial Anesthesia Techniques for Obstetric Care in a Ghanaian Referral Hospital. Obstetric Anesthesia Digest. 2016; 36(1): 9. https : //doi.org/10.1097/01.aoa.0000479480.88730.e3

[19] Bode CO, Olatosi J, Amposah G, et al. Has the middle-level anaesthesia manpower training program of the West African College of Surgeons fulfilled its objectives? Anaesthesia \& Intensive Care. 2013; 41(3). PMid:23659398 https ://doi .org/10.1177/0310 $057 \mathrm{X} 1304100313$

[20] Kasparian L. Sleeping in Safety: A Study of Nurse Anesthetists in Ghana. Inquiry Journal. 2011. Available from: https://scholars .unh.edu/inquiry_2011/9

[21] Löhnert H. Health care and regional anesthesia education for nurse anesthetists in Ghana. CRNA: The Clinical Forum for Nurse Anesthetists. 2000; 11(3): 99-102.

[22] Otchi E, Bannerman C, Lartey S, et al. Patient safety situational analysis in Ghana. Journal of Patient Safety and Risk Management 2018. https://doi.org/10.1177/2516043518806366

[23] Tabiri S, Russell KW, Gyamfi FE, et al. Local anesthesia underutilized for inguinal hernia repair in northern Ghana. PLOS ONE. 2018; 13(11): e0206465. PMid:30462684 https ://doi.org/10.1371/ journal.pone. 0206465 